\title{
Review \\ Acute Pulmonary Embolism: Prognostic Role of Computed Tomography Pulmonary Angiography (CTPA)
}

\author{
Giulia Zantonelli ${ }^{1}$, Diletta Cozzi ${ }^{1,2}{ }^{*}{ }^{\mathbb{D}}$, Alessandra Bindi ${ }^{1}$, Edoardo Cavigli ${ }^{1}$, Chiara Moroni ${ }^{1}$, Silvia Luvarà ${ }^{1}$, \\ Giulia Grazzini ${ }^{1}$, Ginevra Danti ${ }^{1}$ (D), Vincenza Granata ${ }^{3}$ and Vittorio Miele ${ }^{1}$ (D)
}

1 Emergency Radiology, Careggi University Hospital, 50134 Florence, Italy; giulia.zanto@gmail.com (G.Z.); bindi.alessandra@gmail.com (A.B.); edoardocavigli@yahoo.it (E.C.); chiaramoroni73@gmail.com (C.M.); luvaras@aou-careggi.toscana.it (S.L.); grazzini.giulia@gmail.com (G.G.); ginevra.danti@gmail.com (G.D.); vmiele@sirm.org (V.M.)

2 Italian Society of Medical and Interventional Radiology (SIRM), SIRM Foundation, 20122 Milan, Italy

3 Radiology Division, Istituto Nazionale Tumori IRCCS Fondazione Pascale, 80131 Naples, Italy; v.granata@istitutotumori.na.it

* Correspondence: dilettacozzi@gmail.com

Citation: Zantonelli, G.; Cozzi, D.; Bindi, A.; Cavigli, E.; Moroni, C.;

Luvarà, S.; Grazzini, G.; Danti, G.;

Granata, V.; Miele, V. Acute

Pulmonary Embolism: Prognostic Role of Computed Tomography Pulmonary Angiography (CTPA) Tomography 2022, 8, 529-539. https: / /doi.org/10.3390/ tomography 8010042

Academic Editors: Stefania Tamburrini and Mariano Scaglione

Received: 16 January 2022

Accepted: 8 February 2022

Published: 14 February 2022

Publisher's Note: MDPI stays neutral with regard to jurisdictional claims in published maps and institutional affiliations.

Copyright: (C) 2022 by the authors. Licensee MDPI, Basel, Switzerland. This article is an open access article distributed under the terms and conditions of the Creative Commons Attribution (CC BY) license (https:// creativecommons.org/licenses/by/ $4.0 /)$.

\begin{abstract}
Computed Tomography Pulmonary Angiography (CTPA) is considered the gold standard diagnostic technique in patients with suspected acute pulmonary embolism in emergency departments. Several studies have been conducted on the predictive value of CTPA on the outcomes of pulmonary embolism (PE). The purpose of this article is to provide an updated review of the literature reporting imaging parameters and quantitative $\mathrm{CT}$ scores to predict the severity of PE.
\end{abstract}

Keywords: pulmonary embolism; CTPA; vascular; emergency

\section{Introduction}

Pulmonary embolism (PE) is defined by embolic occlusion of the pulmonary arterial system. PE is the third most frequently occurring cause of cardiovascular death after stroke and myocardial infarction, causing $\geq 300,000$ deaths per year in the US [1,2]. Right ventricular dysfunction (RVD), defined as a rapidly progressive congestion syndrome resulting from impaired filling and/or reduced flow out of the right ventricle, triggered by acute pressure overload, is the leading cause of death in severe PE [3]. Signs of RVD and hemodynamic instability, such as tachycardia, low systolic blood pressure, respiratory failure, and syncope, are associated with a poor prognosis and a high risk of early mortality (within 30 days) [3]. Another, albeit late but potentially fatal, consequence of PE is the development of chronic pulmonary hypertension.

Among imaging tests, Computed Tomography Pulmonary Angiography (CTPA) is considered the first-line diagnostic technique in patients with suspected PE with sensitivity and specificity values between 96 and 100\% and between 89 and 98\%, respectively [4]. In the European Society of Cardiology guidelines, CTPA is indicated as Class IC in patients with high suspicion of PE, even if hemodynamically unstable [5]. Moreover, if the CTPA is regular in patients with low or intermediate clinical probability, the diagnosis of PE can be ruled out without further testing (Class IA) [5]. On the other hand, over-testing for PE remains a major health problem, especially in University hospitals [6,7]. In fact, it is estimated that $9.4 \%$ of CTPA could be avoided [8]. In addition, several studies have been performed on the potential role of CTPA as an ancillary tool in establishing patient prognosis in PE [9-12].

This article aims to provide an updated review of the literature reporting imaging parameters and quantitative Computed Tomography (CT) scores useful in predicting PE severities to identify patients who need aggressive therapy or intensive observation. 


\section{Pulmonary Artery Clots Burden Indexes}

The degree of clot obstruction within the pulmonary arterial tree can be estimated using four different indexes. The first angiographic scores adapted to spiral CT were those of Walsh and Miller [13]. Subsequently, Qanadli et al. and Mastora et al. proposed two different indexes specifically studied for CTPA to quantitatively assess the severity of acute PE [14,15]. The CT Obstruction Index (CTOI) as described by Qanadli et al. is calculated as the sum of the individual scores per artery divided by 40 (the maximum total score) and converted into a percentage. The unit score per artery is calculated by attributing a unit value to each segmental pulmonary artery with thromboembolism (max 10 for each lung) and multiplying it by a weight factor ( 1 for partial obstruction or 2 for total obstruction) [14]. Mastora et al. described an index like CTOI, which is also related to some appreciable findings on echocardiography, such as the presence of pulmonary hypertension and cor pulmonale [15]. Currently, the Qanadli index is commonly used to assess the severity of acute pulmonary embolism (APE) at the CTPA. As suggested by the Authors, two groups of patients are identified. The high-risk subgroup has a CTOI $\geq 20$ and the low-risk subgroup has a CTOI $<20$ [14]. The ability to select high-risk PE patients using pulmonary obstruction indexes was examined by several studies. Faghihi Langroudi et al. investigated the association between CTOI and atrial size in patients with APE, showing that higher clot load is associated with smaller (left atrium) LA size and increased (right atrium) RA/LA ratios [16]. In a small study of 35 patients with PE, Praveen Kumar et al. found that CTOI was a strong independent predictor of RVD in PE, linearly correlating to several variables associated with increased morbidity and mortality, allowing an accurate risk stratification selection of patients who needed more aggressive treatment [17]. Rotzinger et al. recently reported that patients with PE, excluding those with cardiopulmonary comorbidities or pulmonary neoplasms and with CTOI greater than $40 \%$, had significantly higher mortality $(p<0.001)$ than those with CTOI less than $20 \%$ [18]. Patients with PE, cardiopulmonary comorbidities, or pulmonary neoplasms had an increased risk of fatal outcomes regardless of CTOI. Nevertheless, the time required for the data analysis would be significantly reduced using computer-assisted techniques such as artificial intelligence, increasing the reliability of vascular obstruction indexes (both CTOI and Mastora), reducing time and costs, and providing additional quantitative parameters for severity disease assessment [19].

\section{Predictor Findings}

\section{1. $R V / L V$ Ratio}

As reported by Aribas et al., cardiac chamber diameters should be measured in the short-axis plane. Right ventricle (RV) and left ventricle (LV) diameters are required to calculate the RV/LV ratio [20]. The ratio of RV/LV short axis in CTPA $>1$ is a surrogate marker for RV dysfunction because it correlates with the increase in afterload induced by acute embolism on ventricular function. Several studies validated its role as a predictor of short-term mortality (within 30 days) and adverse clinical events in patients with acute PE $[9,12,21]$. Ayöz et al. described higher troponin levels in patients with RV/LV > 1 [22]. Moreover, in a study by Cho et al., an RV/LV diameter ratio greater than 1 was associated with an increased risk of 2.4 admissions to the intensive care unit [21] (Figure 1).

\subsection{Diameter of Pulmonary Artery}

Main pulmonary artery (PA) diameters and the ratio of the pulmonary artery to the ascending aorta have been suggested as indicators of pulmonary hypertension. In a recent study, a significant increase in pulmonary $(p=0.003)$ and aortic $(p=0.006)$ diameter was seen in patients who succumbed to PE compared with those who survived [22]. Furthermore, according to Lyhne et al., an increase in PA diameter led to serious adverse events. In their study, the median PA diameter in patients with adverse outcomes was $29.9 \mathrm{~mm}$ (CI 21.8-32.4 mm) $(p=0.014)$ [23] (Figure 2). 


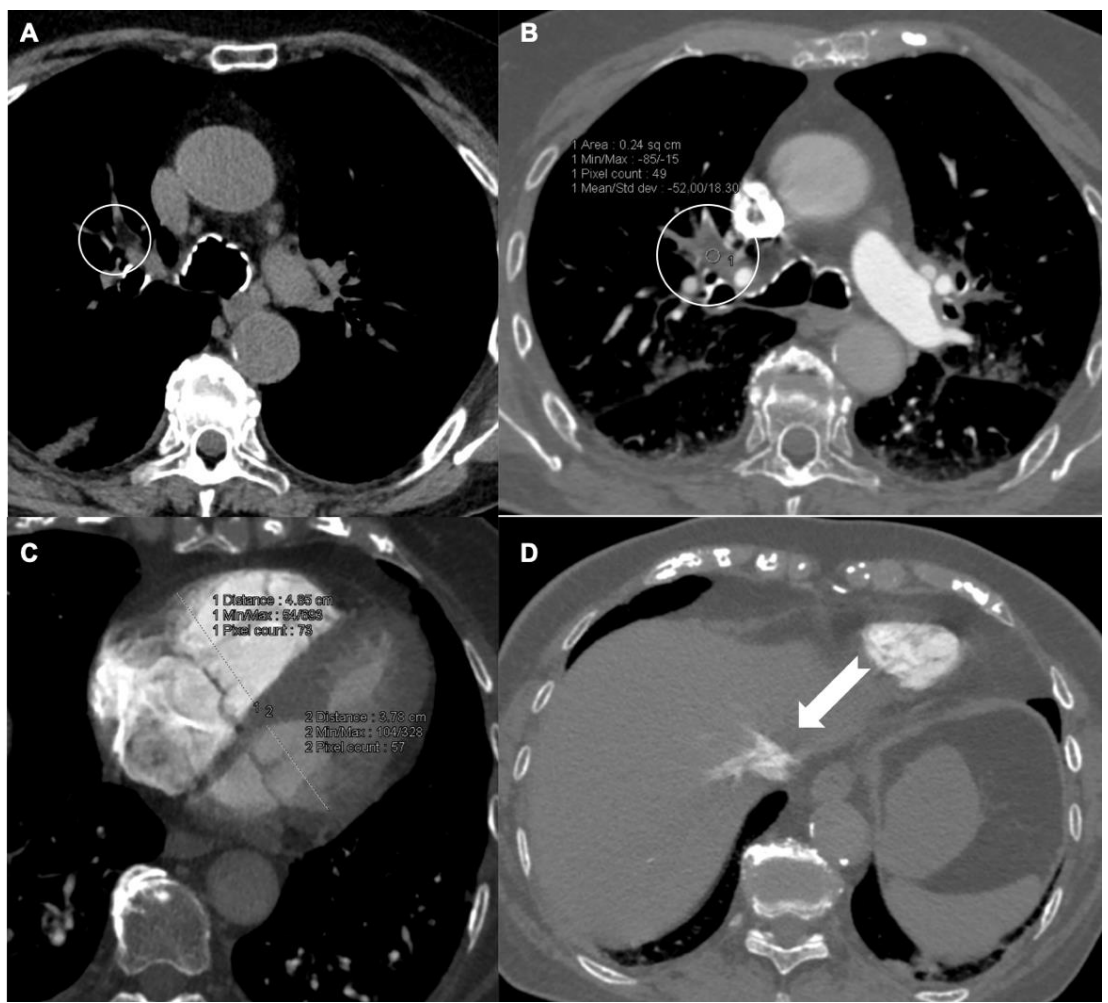

Figure 1. Patient with fat-filling defects in the right upper lobar pulmonary artery in non-contrast (A) and contrast (B) axial scans. (C) CTPA illustration of RV/LV diameter ratio measurement; the measurement in this patient was 1.26. ((D), arrow) Reflux of contrast medium extended to hepatic veins (grade III).

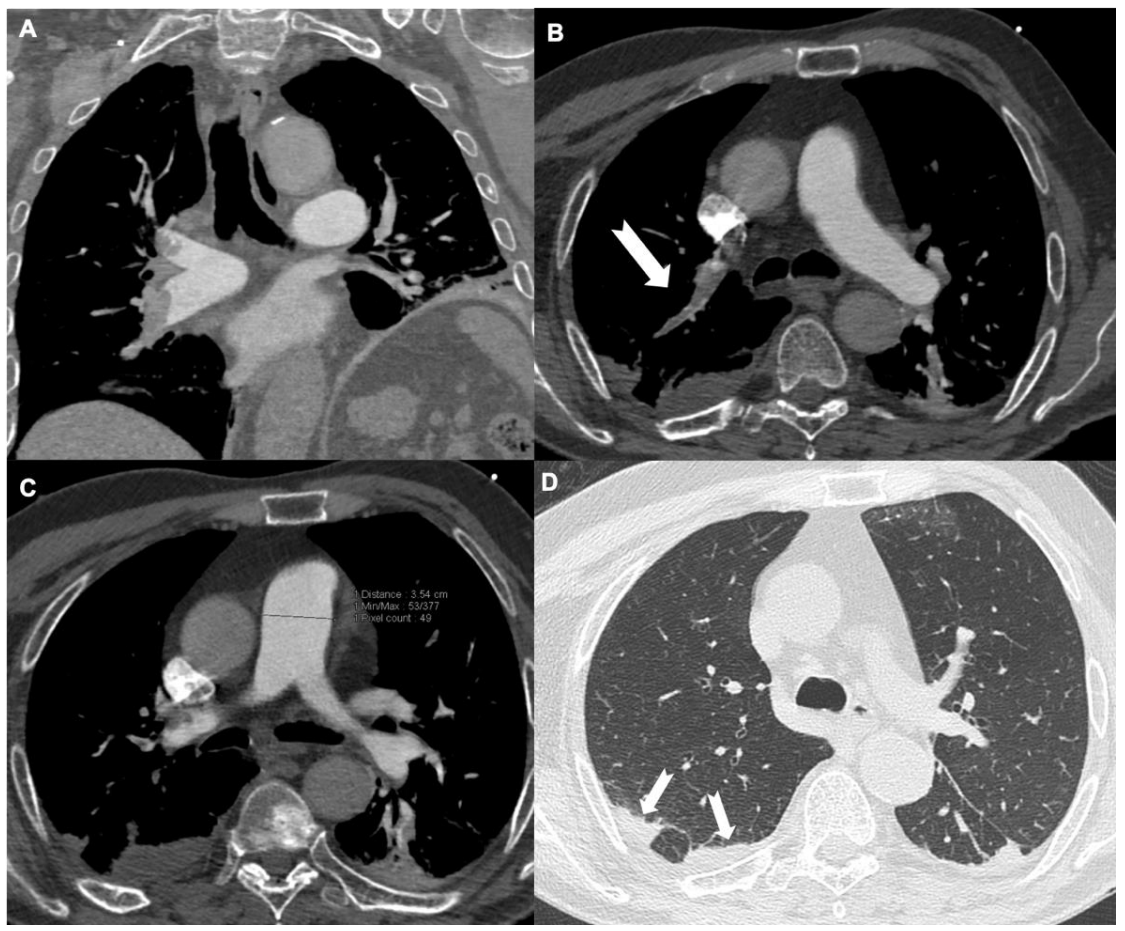

Figure 2. Patient with embolism involving pulmonary arterial branches for the right upper and lower lobe (A) and a sub-segmental branch for the right upper lobe ((B), arrow). Pulmonary arterial trunk dilatation (35.4 mm) (C) and multiple pulmonary infarctions ((D), arrows) are shown. 


\subsection{Diameter of Coronary Sinus}

Recently, Cozzi et al. showed that coronary sinus dilatation $(>9 \mathrm{~mm})$ is related to an increased risk of all-cause death within 30 days $(p<0.05)$. Compared to the RV/LV ratio, this is poorly affected by changes in the cardiac cycle, contractile motion artifacts, or heart diseases. Therefore, the use of this parameter can provide additional results in predicting outcomes [9] (Figure 3).

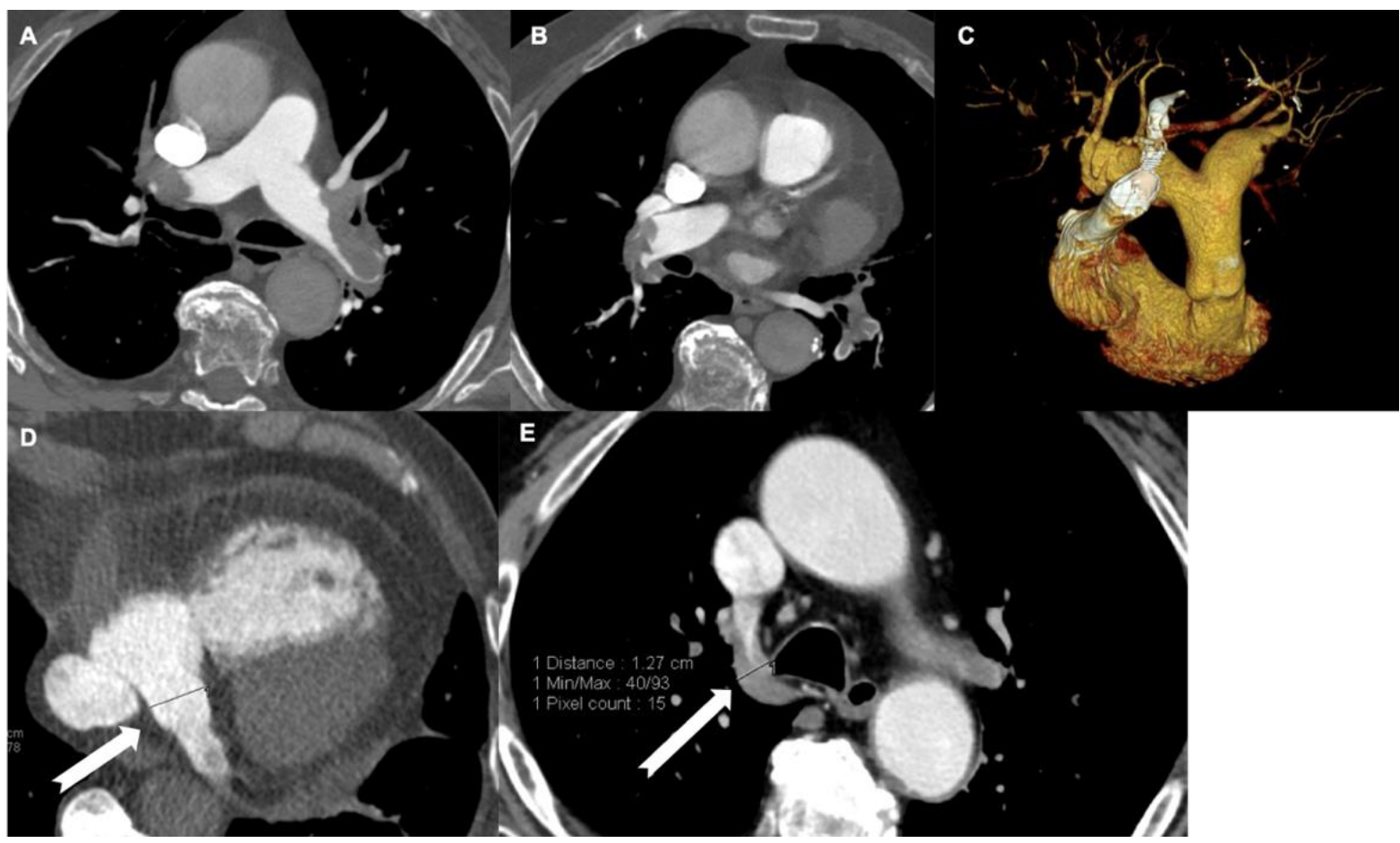

Figure 3. Increase in the diameter of the veins and embolism. A middle-aged man with huge eccentric emboli attached to the vascular wall of both pulmonary arteries (A-C). (D) Dilatation of the coronary sinus (arrow); the measurement in this patient was $21 \mathrm{~mm}$. Dilatation of the azygos vein $(12.7 \mathrm{~mm})(\mathrm{E})$.

\subsection{Inferior Vena Cava Reflux}

Contrast reflux into the inferior vena cava (IVC) is secondary to right heart failure. The degree of reflux can be quantified on a three-point scale where grade I does not indicate reflux in the IVC, grade II suggests subcardial reflux in IVC, and grade III identifies intrahepatic reflux in IVC $[24,25]$. Several studies showed a positive correlation between IVC contrast reflux and poor prognosis [22,26]. In particular, in the study by Ayöz et al., IVC reflux was present in $81.3 \%(p=0.001)$ of patients who succumbed. Furthermore, patients with an RV/LV ratio $\geq 1$ had IVC reflux more frequently $(p=0.025)$ than patients with an $\mathrm{RV} / \mathrm{LV}$ ratio $<1[22]$.

\subsection{Displacement of the Interventricular Septum}

The interventricular septum normally bends towards the RV; however, due to the increase in pressure in the right heart sections, it can move towards the LV. Ventricular septum bowing has excellent specificity $(100 \%)$ but poor sensitivity $(26 \%)$ in predicting RV dysfunction [27]. However, in the study by Shayganfar et al., abnormal septal morphology was significantly more common among patients with high-risk PE $(p<0.01)$ [10]. The abnormal septal placement is a negative predictor in both CTPA and echocardiography, albeit not consistently. For instance, in a meta-analysis by Meinel et al., the presence of the septal curvature was associated to all-cause mortality $(p=0.002)$, PE-related mortality $(p=0.0067)$, and adverse clinical outcomes $(p=0.0008)$ [28]. 
Lyhne et al. recently failed ( $p=0.055)$ in demonstrating that the leftward curvature of the ventricular septum positively matched with more than twice the risk of clinical deterioration in patients with acute PE [23].

\subsection{Left Atrial Size}

The abrupt increase in pulmonary vascular resistance, which follows thromboembolic obstruction, can lead to RVD and failure. Subsequently, a decrease in pulmonary venous return with an insufficient filling of the LA may occur.

Several studies validated the use of LA sizes as a prognostic tool in patients with PE [16,29-31]. According to Guo et al., the left-to-right diameter and anterior-posterior diameter of LA showed a positive correlation with the prognosis of PE [31]. A reduced volume of LA was the best predictor of an adverse outcome, according to Aviram et al. [30]. In their study, they found a higher mortality rate among patients with an LA volume $<62 \mathrm{~mL}$ compared to those with an LA volume $>62 \mathrm{~mL}(19.6 \%$ vs. $8.9 \%$, respectively; $p<0.001)$. Recently, in a study performed on 350 patients diagnosed with acute PE, the reduction in the volume of LA showed a positive correlation with adverse events $(p \leq 0.01)$ and death $(p=0.03)$ related to PE [30].

\subsection{Pulmonary Artery Distensibility}

Pulmonary artery distensibility (PAD) has proven to be a sensitive and specific marker for pulmonary hypertension [32]. Recently, the use of ECG-gated retrospective CTPA in the assessment of PAD has been investigated [33,34]. As reported by Liang et al., artery distensibility can be calculated using the following formula:

$$
\mathrm{PAD}=([S s-S d] / S d) /(S B P-D B P)
$$

where $S s$ and $S d$ indicate the maximum and minimum luminal area, respectively; $S B P$ defines the systolic blood pressure, and DBP indicates the diastolic blood pressure [35]. As suggested by Wang et al., measurements must be established on a section of the main PA, conventionally halfway between its origin and its bifurcation, adjusted to be perpendicular to the longitudinal axis in both the axial and coronal planes [36]. Furthermore, according to Wang et al., through PAD, the use of retrospective ECG-gated CTPA would allow providing information on cardiac function and assessing the stratification of APE risk [36].

\subsection{Coronary Artery Calcifications}

Coronary artery calcifications act as an important determinant of coronary artery disease [37]. Patients undergoing CT for suspected PE are more likely to have coronary artery calcifications [38]. Few studies in the literature have investigated the importance of coronary artery calcifications on both short- and long-term mortality in patients with APE $[39,40]$. Ng et al, in their study of 1023 patients diagnosed with PE, showed that long-term all-cause cardiovascular mortality was 2.2 higher than in patients without cardiovascular diseases [41]. Heidinger et al. found that severe or moderate coronary artery calcifications were associated with PE-related 30-day mortality of 9.5\% $(p=0.049)$ and $6.7 \%$ $(p=0.033)$, respectively [40].

\section{COVID-19 Pneumonia}

PE is a common complication in patients with SARS-CoV-2 pneumonia [42]. The triggering cause of PE following an acute infection, especially in the respiratory tract, would be due to local inflammation causing the local activation of coagulation and vasoconstriction. Endothelial dysfunction, a state of hypercoagulation with activation of platelets and leukocytes, and later thrombin generation and widespread fibrin deposition, are related to the increased risk of thromboembolic events in SARS-CoV2 infection $[43,44]$.

Ippolito et al. observed that 76/170 (44.7\%) patients with SARS-CoV-2 developed $\mathrm{PE}$ without having higher risk factors for venous thromboembolism [42]. In addition, PE-positive patients showed slightly longer hospitalization times than PE-negative patients, 
with a mortality rate among PE-positive patients of 54.2\% at three months [42]. Moreover, in the study by Masselli et al., 26/60 (40\%) patients with SARS-CoV-2 were found to be positive for PE at CTPA. In these patients, the probability of being admitted to the intensive care unit was higher than those who did not have PE (19/26 vs. 11/34 patients) and more frequently required mechanical ventilation (15/26 patients vs. 9/34 patients) [45] (Figure 4).

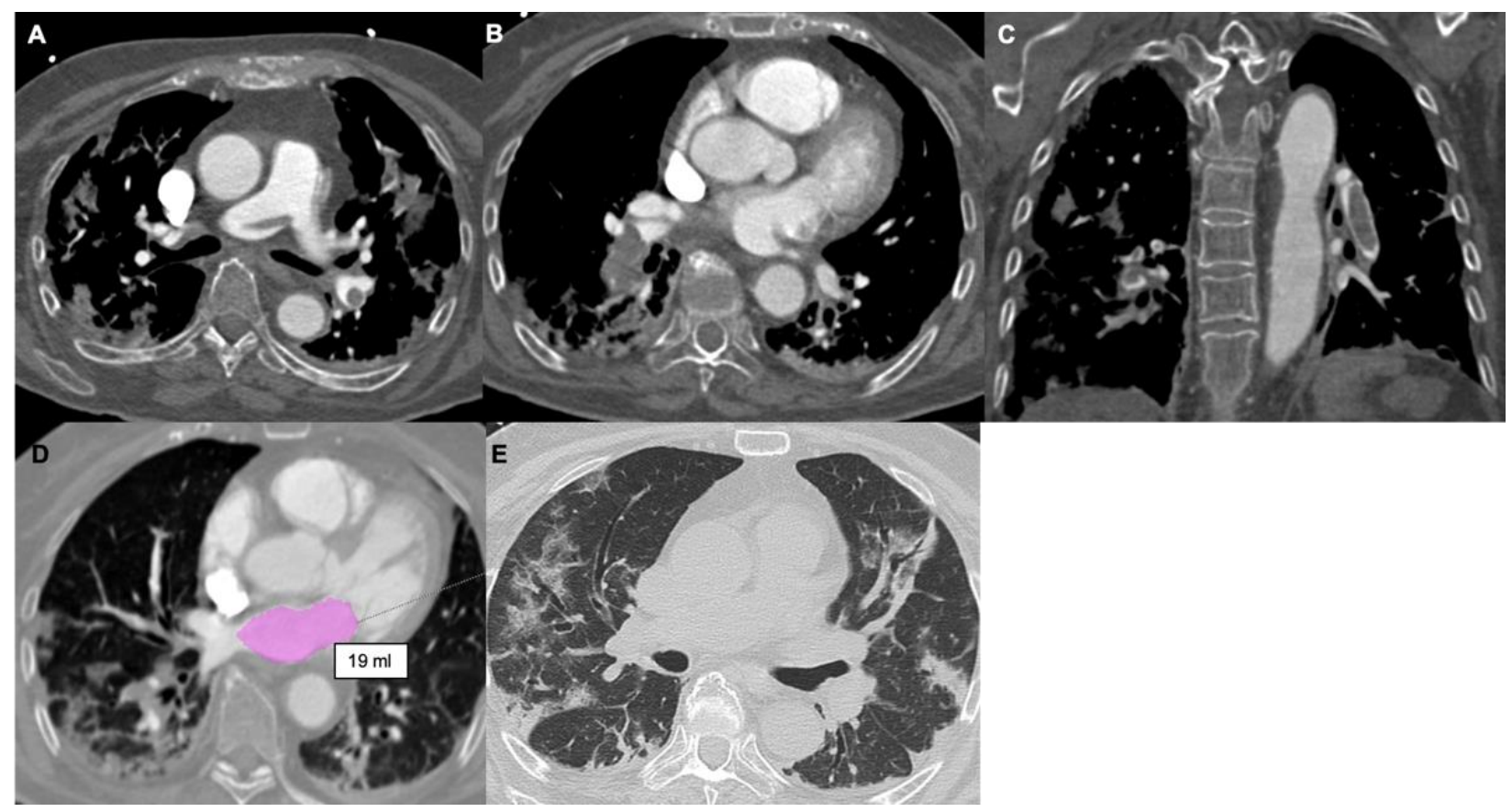

Figure 4. (A,B) Axial and coronal (C) contrast-enhanced CT scans show saddle embolism and multiple eccentric emboli involving the lower lobar branches of the pulmonary arteries. (D) Left atrium, purple. There is decreased LA volume, $19 \mathrm{~mL}$. (E) Axial scans in the lung window show peripheral ground-glass opacities in association with consolidation areas involving both lungs.

\section{Dual Energy CT}

According to recent studies, the use of new CT technologies such as dual-energy computed tomography (DECT) would provide additional information compared to singleenergy CT with lower contrast doses and radiation [46-48]. Using monoenergetic image reconstructions, the attenuation of the vessel and the contrast-noise ratio can be improved while using a small amount of contrast agent.

DECT would allow the simultaneous evaluation of the vascular and parenchymal distribution of iodine in the lungs, allowing the visualization of perfusion defects without an excessive dose of radiation [49-51]. According to some Authors, the detection of peripheral intrapulmonary clots would be improved by the addition of DECT to the CTPA. In their study, Weidman et al. showed that the DECT iodine map allows detecting small pulmonary emboli in $1 \%$ of patients that would otherwise be lost [46]. Several studies showed a positive correlation between perfusion defects, signs of RVD, and PA obstruction [52-54]. On the other hand, according to Monti et al., DECT did not yield additional diagnostic benefits in the detection of patients with APE compared to single CT energy [55].

More studies examined contrast medium volume reduction with DECT [56-59]. Reducing contrast medium volume with the application of DECT can help patients with impaired renal function, which is most commonly seen among those who have a high risk of PE [60]. However, also concerning CTPA, in recent years some strategies have been developed to optimize its technical parameters (e.g., reduced acquisition time, low-kVp protocols, high pitch imaging) [61,62]. 
Recent studies demonstrated the feasibility of performing CTPA using a minimal amount of iodinated contrast medium while maintaining sufficient image quality to exclude or diagnose PE $[63,64]$.

Silva et al., compared protocols performed with 20 or $40 \mathrm{~mL}$ contrast medium in patients with suspected PE [65]. In both protocols, vascular contrast enhancement was $>250 \mathrm{HU}$, thus demonstrating that $20 \mathrm{~mL}$ contrast medium administration was sufficient for the evaluation of pulmonary arteries in patients with a clinical suspicion of APE [65] (Figure 5).

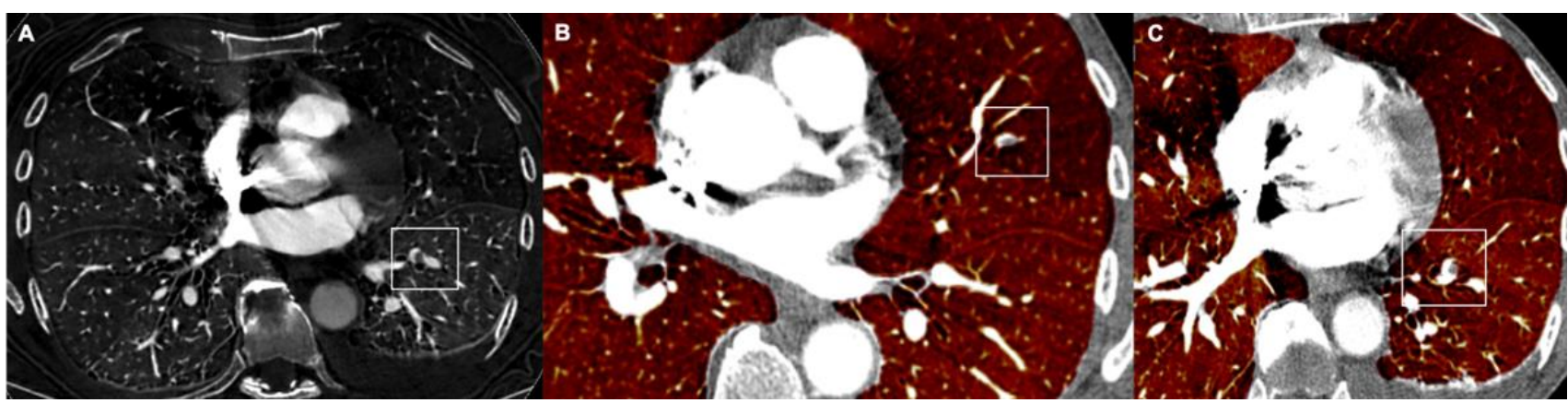

Figure 5. (A) The DECT iodine map allows for the detection of small pulmonary emboli in the left lower lobe. Simultaneous evaluation of the vascular and parenchymal distribution of iodine in the lungs with relief of a small embolus in the lingula (B) and the left lower lobe (C).

\section{Conclusions}

CTPA is a first-line tool for APE diagnosis that is also capable of quantifying PE severities with high accuracy, wide availability, and fast response times. Using a minimal amount of contrast medium $(20 \mathrm{~mL})$, it is still possible to maintain an image quality necessary to exclude or diagnose PE.

Author Contributions: Conceptualization, V.M., and D.C.; writing-original draft preparation, G.Z.; writing-review and editing, D.C., E.C., A.B., C.M. and S.L.; visualization, G.D. and G.G.; supervision, V.G.; project administration, V.M. All authors have read and agreed to the published version of the manuscript.

Funding: This research received no external funding.

Institutional Review Board Statement: Not applicable.

Informed Consent Statement: Not applicable.

Data Availability Statement: Not applicable.

Conflicts of Interest: The authors declare no conflict of interest.

$\begin{array}{ll}\text { Abbreviations } \\ \text { APE } & \text { Acute pulmonary embolism } \\ \text { CTOI } & \text { CT Obstruction Index } \\ \text { CTPA } & \text { Computed Tomography Pulmonary Angiography } \\ \text { IVC } & \text { Inferior vena cava } \\ \text { LA } & \text { Left atrium } \\ \text { LV } & \text { Left ventricle } \\ \text { PA } & \text { Pulmonary artery } \\ \text { PAD } & \text { Pulmonary artery distensibility } \\ \text { PE } & \text { Pulmonary embolism } \\ \text { RA } & \text { Right atrium } \\ \text { RV } & \text { Right ventricle } \\ \text { RVD } & \text { Right ventricular dysfunction }\end{array}$




\section{References}

1. Raskob, G.E.; Angchaisuksiri, P.; Blanco, A.N.; Buller, H.; Gallus, A.; Hunt, B.J.; Hylek, E.M.; Kakkar, A.; Konstantinides, S.V.; McCumber, M.; et al. Thrombosis: A major contributor to global disease burden. Arterioscler. Thromb. Vasc. Biol. 2014, 34, 2363-2371. [CrossRef] [PubMed]

2. Wendelboe, A.M.; Raskob, G.E. Global Burden of Thrombosis: Epidemiologic Aspects. Circ. Res. 2016, 118, 1340-1347. [CrossRef] [PubMed]

3. Harjola, V.P.V.; Mebazaa, A.; Čelutkiene, J.J.; Bettex, D.D.; Bueno, H.; Chioncel, O.O.; Crespo-Leiro, M.G.; Falk, V.; Filippatos, G.; Gibbs, S.S.; et al. Contemporary management of acute right ventricular failure: A statement from the Heart Failure Association and the Working Group on Pulmonary Circulation and Right Ventricular Function of the European Society of Cardiology. Eur. J. Hear. Fail. 2016, 18, 226-241. [CrossRef] [PubMed]

4. $\quad$ Stein, P.D.; Fowler, S.E.; Goodman, L.R.; Gottschalk, A.; Hales, C.A.; Hull, R.D.; Leeper, K.V., Jr.; Popovich, J., Jr.; Quinn, D.A.; Sos, T.A.; et al. Multidetector Computed Tomography for Acute Pulmonary Embolism. N. Engl. J. Med. 2006, 354, $2317-2327$. [CrossRef]

5. Konstantinides, S.V.; Meyer, G.; Becattini, C.; Bueno, H.; Geersing, G.-J.; Harjola, V.; Huisman, M.V.; Humbert, M.; Jennings, C.S.; Jiménez, D.; et al. 2019 ESC Guidelines for the diagnosis and management of acute pulmonary embolism developed in collaboration with the European respiratory society (ERS). Eur. Heart J. 2020, 41, 543-603. [CrossRef]

6. Kline, J.A.; Garrett, J.S.; Sarmiento, E.J.; Strachan, C.C.; Courtney, D.M. Over-testing for suspected pulmonary embolism in American emergency departments: The continuing epidemic. Circ. Cardiovasc. Qual. Outcomes 2020, 13, e005753. [CrossRef]

7. Raji, H.; Moosavi, S.A.J.; Dastoorpoor, M.; Mohamadipour, Z.; Ghanavati, P.M. Overuse and underuse of pulmonary CT angiography in patients with suspected pulmonary embolism. Med. J. Islam. Repub. Iran 2018, 32, 13-17. [CrossRef]

8. Mirabile, A.; Lucarelli, N.M.; Sollazzo, E.P.; Stabile Ianora, A.A.; Sardaro, A.; Mirabile, G.; Lorusso, F.; Racanelli, V.; Maggialetti, N.; Scardapane, A. CT pulmonary angiography appropriateness in a single emergency department: Does the use of revised Geneva score matter? Radiol. Med. 2021, 126, 1544-1552. [CrossRef]

9. Cozzi, D.; Moroni, C.; Cavigli, E.; Bindi, A.; Caviglioli, C.; Nazerian, P.; Vanni, S.; Miele, V.; Bartolucci, M. Prognostic value of CT pulmonary angiography parameters in acute pulmonary embolism. Radiol. Med. 2021, 126, 1030-1036. [CrossRef]

10. Shayganfar, A.; Hajiahmadi, S.; Astaraki, M.; Ebrahimian, S. The assessment of acute pulmonary embolism severity using CT angiography features. Int. J. Emerg. Med. 2020, 13, 1-5. [CrossRef]

11. Wells, P.; Peacock, W.F.; Fermann, G.J.; Coleman, C.I.; Wang, L.; Baser, O.; Schein, J.; Crivera, C. The value of sPESI for risk stratification in patients with pulmonary embolism. J. Thromb. Thrombolysis 2019, 48, 149-157. [CrossRef]

12. Apfaltrer, P.; Henzler, T.; Meyer, M.; Roeger, S.; Haghi, D.; Gruettner, J.; Süselbeck, T.; Wilson, R.; Schoepf, U.; Schoenberg, S.; et al Correlation of CT angiographic pulmonary artery obstruction scores with right ventricular dysfunction and clinical outcome in patients with acute pulmonary embolism. Eur. J. Radiol. 2012, 81, 2867-2871. [CrossRef]

13. Bankier, A.A.; Janata, K.; Fleischmann, D.; Kreuzer, S.; Mallek, R.; Frossard, M.; Domanovits, H.; Herold, C.J. Severity Assessment of Acute Pulmonary Embolism with Spiral CT. J. Thorac. Imaging 1997, 12, 150-158. [CrossRef]

14. Qanadli, S.D.; El Hajjam, M.; Vieillard-Baron, A.; Joseph, T.; Mesurolle, B.; Oliva, V.L.; Barré, O.; Bruckert, F.; Dubourg, O.; Lacombe, P. New CT Index to Quantify Arterial Obstruction in Pulmonary Embolism. Am. J. Roentgenol. 2001, 176, 1415-1420. [CrossRef]

15. Mastora, I.; Remy-Jardin, M.; Masson, P.; Galland, E.; Delannoy, V.; Bauchart, J.-J.; Remy, J. Severity of acute pulmonary embolism: Evaluation of a new spiral CT angiographic score in correlation with echocardiographic data. Eur. Radiol. 2003, 13, 29-35. [CrossRef]

16. Faghihi Langroudi, T.; Sheikh, M.; Naderian, M.; Sanei Taheri, M.; Ashraf-ganjouei, A.; Khaheshi, I. The Association between the Pulmonary Arterial Obstruction Index and Atrial Size in Patients with Acute Pulmonary Embolism. Radiol. Res. Pract. 2019, 2019, 6025931. [CrossRef]

17. Praveen Kumar, B.S.; Rajasekhar, D.; Vanajakshamma, V. Study of clinical, radiological and echocardiographic features and correlation of Qanadli CT index with RV dysfunction and outcomes in pulmonary embolism. Indian Heart J. 2014, 66, 629-634. [CrossRef]

18. Rotzinger, D.C.; Knebel, J.-F.; Jouannic, A.-M.; Adler, G.; Qanadli, S.D. CT Pulmonary Angiography for Risk Stratification of Patients with Nonmassive Acute Pulmonary Embolism. Radiol. Cardiothorac. Imaging 2020, 2, e190188. [CrossRef]

19. Sun, Z.-T.; Hao, F.-E.; Guo, Y.-M.; Liu, A.-S.; Zhao, L. Assessment of Acute Pulmonary Embolism by Computer-Aided Technique: A Reliability Study. Med. Sci. Monit. 2020, 26, e920239. [CrossRef]

20. Aribas, A.; Keskin, S.; Akilli, H.; Kayrak, M.; Erdogan, H.I.; Guler, I.; Yildirim, O.; Bekci, T.T. The use of axial diameters and CT obstruction scores for determining echocardiographic right ventricular dysfunction in patients with acute pulmonary embolism. Jpn. J. Radiol. 2014, 32, 451-460. [CrossRef]

21. Cho, S.-U.; Cho, Y.-D.; Choi, S.-H.; Yoon, Y.-H.; Park, J.-H.; Park, S.-J.; Lee, E.-S. Assessing the severity of pulmonary embolism among patients in the emergency department: Utility of RV/LV diameter ratio. PLoS ONE 2020, 15, e0242340. [CrossRef] 
22. Ayöz, S.; Erol, S.; Kul, M.; Kaya, A.G.; Çoruh, A.G.; Savaş, I.; Aydın, Ö.; Kaya, A. Using RV/LV ratio and cardiac biomarkers to define the risk of mortality from pulmonary embolism. Tuberk. Toraks 2021, 69, 297-306. [CrossRef]

23. Lyhne, M.D.; Schultz, J.G.; MacMahon, P.J.; Haddad, F.; Kalra, M.; Tso, D.M.K.; Muzikansky, A.; Lev, M.H.; Kabrhel, C. Septal bowing and pulmonary artery diameter on computed tomography pulmonary angiography are associated with short-term outcomes in patients with acute pulmonary embolism. Emerg. Radiol. 2019, 26, 623-630. [CrossRef]

24. Groves, A.; Win, T.; Charman, S.; Wisbey, C.; Pepke-Zaba, J.; Coulden, R. Semi-quantitative assessment of tricuspid regurgitation on contrast-enhanced multidetector CT. Clin. Radiol. 2004, 59, 715-719. [CrossRef]

25. Aviram, G.; Cohen, D.; Steinvil, A.; Shmueli, H.; Keren, G.; Banai, S.; Berliner, S.; Rogowski, O. Significance of Reflux of Contrast Medium Into the Inferior Vena Cava on Computerized Tomographic Pulmonary Angiogram. Am. J. Cardiol. 2012, $109,432-437$. [CrossRef]

26. Bach, A.G.; Nansalmaa, B.; Kranz, J.; Taute, B.-M.; Wienke, A.; Schramm, D.; Surov, A. CT pulmonary angiography findings that predict 30-day mortality in patients with acute pulmonary embolism. Eur. J. Radiol. 2015, 84, 332-337. [CrossRef]

27. Seon, H.J.; Kim, K.H.; Lee, W.S.; Choi, S.; Yoon, H.J.; Ahn, Y.; Kim, Y.-H.; Jeong, M.H.; Cho, J.G.; Park, J.C.; et al. Usefulness of Computed Tomographic Pulmonary Angiography in the Risk Stratification of Acute Pulmonary Thromboembolism-Comparison With Cardiac Biomarkers. Circ. J. 2011, 75, 428-436. [CrossRef]

28. Meinel, F.; Nance, J.W.; Schoepf, U.J.; Hoffmann, V.S.; Thierfelder, K.M.; Costello, P.; Goldhaber, S.Z.; Bamberg, F. Predictive Value of Computed Tomography in Acute Pulmonary Embolism: Systematic Review and Meta-analysis. Am. J. Med. 2015, 128, 747-759.e2. [CrossRef]

29. Zuin, M.; Rigatelli, G.; Turchetta, S.; Zonzin, P.; Zuliani, G.; Roncon, L. Left atrial size measured on CT pulmonary angiography: Another parameter of pulmonary embolism severity? A systematic review. J. Thromb. Thrombolysis 2019, 50, 181-189. [CrossRef]

30. Aviram, G.; Soikher, E.; Bendet, A.; Shmueli, H.; Ziv-Baran, T.; Amitai, Y.; Friedensohn, L.; Berliner, S.; Meilik, A.; Topilsky, Y. Prediction of Mortality in Pulmonary Embolism Based on Left Atrial Volume Measured on CT Pulmonary Angiography. Chest 2016, 149, 667-675. [CrossRef]

31. Guo, Z.-J.; Liu, H.-T.; Bai, Z.-M.; Lin, Q.; Zhao, B.-H.; Xu, Q.; Zeng, Y.-H.; Feng, W.-Q.; Zhou, H.-T.; Liang, F.; et al. A new method of $\mathrm{CT}$ for the cardiac measurement: Correlation of computed tomography measured cardiac parameters and pulmonary obstruction index to assess cardiac morphological changes in acute pulmonary embolism patients. J. Thromb. Thrombolysis 2018, 45, 410-416. [CrossRef] [PubMed]

32. Wu, D.-K.; Hsiao, S.-H.; Lin, S.-K.; Lee, C.-Y.; Yang, S.-H.; Chang, S.-M.; Chiou, K.-R. Main Pulmonary Arterial Distensibility Different Presentation Between Chronic Pulmonary Hypertension and Acute Pulmonary Embolism. Circ. J. 2008, 72, 1454-1459. [CrossRef] [PubMed]

33. Yang, F.; Wang, D.; Cui, S.; Zhu, Y.; Liu, L.; Ji, M.; Zou, D.; Zhao, R.; Liu, Q. Decreased pulmonary artery distensibility as a marker for severity in acute pulmonary embolism patients undergoing ECG-gated CTPA. J. Thromb. Thrombolysis 2021, 51, 748-756. [CrossRef] [PubMed]

34. Kasai, H.; Sugiura, T.; Tanabe, N.; Sakurai, Y.; Yahaba, M.; Matsuura, Y.; Shigeta, A.; Kawata, N.; Sakao, S.; Kasahara, Y.; et al. Electrocardiogram-Gated 320-Slice Multidetector Computed Tomography for the Measurement of Pulmonary Arterial Distensibility in Chronic Thromboembolic Pulmonary Hypertension. PLoS ONE 2014, 9, e111563. [CrossRef] [PubMed]

35. Liang, W.; Chen, D.; Chen, W.; Cheng, G. The ascending aortic elasticity feature in normotensive subjects: Evaluation with coronary CT angiography. Clin. Imaging 2014, 38, 686-692. [CrossRef] [PubMed]

36. Yu, T.; Yuan, M.; Zhang, Q.; Shi, H.; Wang, D. Evaluation of computed tomography obstruction index in guiding therapeutic decisions and monitoring percutanous catheter fragmentation in massive pulmonary embolism. J. Biomed. Res. 2011, 25, 431-437. [CrossRef]

37. Mori, H.; Torii, S.; Kutyna, M.; Sakamoto, A.; Finn, A.V.; Virmani, R. Coronary Artery Calcification and its Progression. JACC Cardiovasc. Imaging 2018, 11, 127-142. [CrossRef]

38. Kiryu, S.; Raptopoulos, V.; Baptista, J.; Hatabu, H. Increased prevalence of coronary artery calcification in patients with suspected pulmonary embolism1. Acad. Radiol. 2003, 10, 840-845. [CrossRef]

39. Williams, M.; Morley, N.; Muir, K.; Reid, J.; van Beek, E.; Murchison, J. Coronary artery calcification is associated with mortality independent of pulmonary embolism severity: A retrospective cohort study. Clin. Radiol. 2019, 74, 973.e7-973.e14. [CrossRef]

40. Heidinger, B.H.; DaBreo, D.; Kirkbride, R.R.; Santos, M.; Carroll, B.J.; Feldman, S.A.; Mohebali, D.; McCormick, I.; Matos, J.D.; Manning, W.J.; et al. Risk assessment of acute pulmonary embolism utilizing coronary artery calcifications in patients that have undergone CT pulmonary angiography and transthoracic echocardiography. Eur. Radiol. 2021, 31, 2809-2818. [CrossRef]

41. Ng, A.C.C.; Chung, T.; Yong, A.S.C.; Wong, H.S.P.; Chow, V.; Celermajer, D.S.; Kritharides, L. Long-Term Cardiovascular and Noncardiovascular Mortality of 1023 Patients with Confirmed Acute Pulmonary Embolism. Circ. Cardiovasc. Qual. Outcomes 2011, 4, 122-128. [CrossRef]

42. Ippolito, D.; Giandola, T.; Maino, C.; Pecorelli, A.; Capodaglio, C.; Ragusi, M.; Porta, M.; Gandola, D.; Masetto, A.; Drago, S.; et al. Acute pulmonary embolism in hospitalized patients with SARS-CoV-2-related pneumonia: Multicentric experience from Italian endemic area. Radiol. Med. 2021, 126, 669-678. [CrossRef] 
43. Helms, J.; Tacquard, C.; Severac, F.; Leonard-Lorant, I.; Ohana, M.; Delabranche, X.; Merdji, H.; Clere-Jehl, R.; Schenck, M.; Gandet, F.F.; et al. High risk of thrombosis in patients with severe SARS-CoV-2 infection: A multicenter prospective cohort study. Intensive Care Med. 2020, 46, 1089-1098. [CrossRef]

44. Ierardi, A.M.; Gaibazzi, N.; Tuttolomondo, D.; Fusco, S.; La Mura, V.; Peyvandi, F.; Aliberti, S.; Blasi, F.; Cozzi, D.; Carrafiello, G.; et al. Deep vein thrombosis in COVID-19 patients in general wards: Prevalence and association with clinical and laboratory variables. La Radiol. Med. 2021, 126, 722-728. [CrossRef]

45. Masselli, G.; Almberger, M.; Tortora, A.; Capoccia, L.; Dolciami, M.; D’Aprile, M.R.; Valentini, C.; Avventurieri, G.; Bracci, S.; Ricci, P. Role of CT angiography in detecting acute pulmonary embolism associated with COVID-19 pneumonia. Radiol. Med. 2021, 126, 1553-1560. [CrossRef]

46. Weidman, E.K.; Plodkowski, A.J.; Halpenny, D.F.; Hayes, S.A.; Perez-Johnston, R.; Zheng, J.; Moskowitz, C.; Ginsberg, M.S. Dual-Energy CT Angiography for Detection of Pulmonary Emboli: Incremental Benefit of Iodine Maps. Radiology 2018, 289, 546-553. [CrossRef]

47. Abdellatif, W.; Ebada, M.A.; Alkanj, S.; Negida, A.; Murray, N.; Khosa, F.; Nicolaou, S. Diagnostic Accuracy of Dual-Energy CT in Detection of Acute Pulmonary Embolism: A Systematic Review and Meta-Analysis. Can. Assoc. Radiol. J. 2020, 72, $285-292$. [CrossRef]

48. Meinel, F.G.; Graef, A.; Bamberg, F.; Thieme, S.F.; Schwarz, F.; Sommer, W.H.; Neurohr, C.; Kupatt, C.; Reiser, M.F.; Johnson, T.R.C. Effectiveness of Automated Quantification of Pulmonary Perfused Blood Volume Using Dual-Energy CTPA for the Severity Assessment of Acute Pulmonary Embolism. Investig. Radiol. 2013, 48, 563-569. [CrossRef]

49. Tao, S.M.; Li, X.; Schoepf, U.J.; Nance, J.W.; Jacobs, B.E.; Zhou, C.S.; Gu, H.F.; Lu, M.J.; Lu, G.M.; Zhang, L.J. Comparison of the effect of radiation exposure from dual-energy CT versus single-energy CT on double-strand breaks at CT pulmonary angiography. Eur. J. Radiol. 2018, 101, 92-96. [CrossRef]

50. Lenga, L.; Trapp, F.; Albrecht, M.H.; Wichmann, J.L.; Johnson, A.A.; Yel, I.; D’Angelo, T.; Booz, C.; Vogl, T.J.; Martin, S.S. Singleand dual-energy CT pulmonary angiography using second- and third-generation dual-source CT systems: Comparison of radiation dose and image quality. Eur. Radiol. 2019, 29, 4603-4612. [CrossRef]

51. Petritsch, B.; Kosmala, A.; Gassenmaier, T.; Weng, A.; Veldhoen, S.; Kunz, A.; Bley, T.A. Diagnosis of Pulmonary Artery Embolism: Comparison of Single-Source CT and 3rd Generation Dual-Source CT using a Dual-Energy Protocol Regarding Image Quality and Radiation Dose. Rofo 2017, 189, 527-536. [CrossRef] [PubMed]

52. Chae, E.J.; Seo, J.B.; Jang, Y.M.; Krauss, B.; Lee, C.W.; Lee, H.J.; Song, K.-S. Dual-Energy CT for Assessment of the Severity of Acute Pulmonary Embolism: Pulmonary Perfusion Defect Score Compared With CT Angiographic Obstruction Score and Right Ventricular/Left Ventricular Diameter Ratio. Am. J. Roentgenol. 2010, 194, 604-610. [CrossRef] [PubMed]

53. Dournes, G.; Verdier, D.; Montaudon, M.; Bullier, E.; Rivière, A.; Dromer, C.; Picard, F.; Billes, M.-A.; Corneloup, O.; Laurent, F.; et al. Dual-energy CT perfusion and angiography in chronic thromboembolic pulmonary hypertension: Diagnostic accuracy and concordance with radionuclide scintigraphy. Eur. Radiol. 2013, 24, 42-51. [CrossRef] [PubMed]

54. Thieme, S.F.; Becker, C.R.; Hacker, M.; Nikolaou, K.; Reiser, M.F.; Johnson, T.R. Dual energy CT for the assessment of lung perfusion-Correlation to scintigraphy. Eur. J. Radiol. 2008, 68, 369-374. [CrossRef]

55. Monti, C.B.; Zanardo, M.; Cozzi, A.; Schiaffino, S.; Spagnolo, P.; Secchi, F.; De Cecco, C.N.; Sardanelli, F. Dual-energy CT performance in acute pulmonary embolism: A meta-analysis. Eur. Radiol. 2021, 31, 6248-6258. [CrossRef]

56. Carrascosa, P.; Capunay, C.; Rodriguez-Granillo, G.A.; Deviggiano, A.; Vallejos, J.; Leipsic, J.A. Substantial iodine volume load reduction in CT angiography with dual-energy imaging: Insights from a pilot randomized study. Int. J. Cardiovasc. Imaging 2014, 30, 1613-1620. [CrossRef]

57. Johansen, C.; Martinsen, A.; Enden, T.; Svanteson, M. The potential of iodinated contrast reduction in dual-energy CT thoracic angiography; an evaluation of image quality. Radiography 2021, 28, 2-7. [CrossRef]

58. Tabari, A.; Gee, M.S.; Singh, R.; Lim, R.; Nimkin, K.; Primak, A.; Schmidt, B.; Kalra, M.K. Reducing Radiation Dose and Contrast Medium Volume With Application of Dual-Energy CT in Children and Young Adults. Am. J. Roentgenol. 2020, $214,1199-1205$. [CrossRef]

59. Nance, J.W.; Henzler, T.; Meyer, M.; Apfaltrer, P.; Braunagel, M.; Krissak, R.; Schoepf, U.J.; Schoenberg, S.O.; Fink, C. Optimization of Contrast Material Delivery for Dual-Energy Computed Tomography Pulmonary Angiography in Patients With Suspected Pulmonary Embolism. Investig. Radiol. 2012, 47, 78-84. [CrossRef]

60. Kumar, G.; Sakhuja, A.; Taneja, A.; Majumdar, T.; Patel, J.; Whittle, J.; Nanchal, R. Pulmonary Embolism in Patients with CKD and ESRD. Clin. J. Am. Soc. Nephrol. 2012, 7, 1584-1590. [CrossRef]

61. Li, X.; Ni, Q.Q.; Schoepf, U.J.; Wichmann, J.L.; Felmly, L.M.; Qi, L.; Kong, X.; Zhou, C.S.; Luo, S.; Zhang, L.J.; et al. 70-kVp High-pitch Computed Tomography Pulmonary Angiography with 40 mL Contrast Agent. Acad. Radiol. 2015, 22, 1562-1570. [CrossRef]

62. Wang, W.; Zhao, Y.E.; Qi, L.; Li, X.; Zhou, C.S.; Zhang, L.J.; Lu, G.M. Prospectively ECG-triggered high-pitch coronary CT angiography at $70 \mathrm{kVp}$ with $30 \mathrm{~mL}$ contrast agent: An intraindividual comparison with sequential scanning at $120 \mathrm{kVp}$ with 60 mL contrast agent. Eur. J. Radiol. 2017, 90, 97-105. [CrossRef] 
63. Suntharalingam, S.; Mikat, C.; Stenzel, E.; Erfanian, Y.; Wetter, A.; Schlosser, T.; Forsting, M.; Nassenstein, K. Submillisievert standard-pitch CT pulmonary angiography with ultra-low dose contrast media administration: A comparison to standard CT imaging. PLoS ONE 2017, 12, e0186694. [CrossRef]

64. Alobeidi, H.; Alshamari, M.; Widell, J.; Eriksson, T.; Lidén, M. Minimizing contrast media dose in CT pulmonary angiography with high-pitch technique. Br. J. Radiol. 2020, 93, 20190995. [CrossRef]

65. Silva, M.; Milanese, G.; Cobelli, R.; Manna, C.; Rasciti, E.; Poggesi, S.; Sverzellati, N. CT angiography for pulmonary embolism in the emergency department: Investigation of a protocol by $20 \mathrm{ml}$ of high-concentration contrast medium. Radiol. Med. 2019, 125, 137-144. [CrossRef] 